\title{
PROPOSTA DE PLANO DE RETOMADA ACADÊMICA DO CENTRO DE TECNOLOGIA DA UNIVERSIDADE FEDERAL DO CEARÁ
}

Mateus F.P.da Silva-mateuspeixoto@alu.ufc.br

Curso de Engenharia Civil - Universidade Federal do Ceará

Campus do Pici, Bloco 708

60020-181 - Fortaleza - Ceará

Resumo: A ocorrência da pandemia do COVID-19 forçou a interrupção de inúmeras atividades presenciais. Nesse contexto, a educação universitária foi diretamente atingida, visto que muitos métodos de ensino estão ainda sustentados em aulas presenciais, expositivas e orais. O Ceará atingiu altos níveis de infecção pelo coronavírus em março de 2020, o que embasou o provimento da Reitoria da UFC para a interrupção das funções presenciais e seu exercício em modo remoto. Desse modo, o Centro de Tecnologia (CT) da UFC compreende os cursos de Arquitetura, Design e Engenharia; os quais estão em fase de reforma das Propostas Pedagógicas Curriculares e por isso em discussão de novas e ativas metodologias de ensino e aprendizagem. Diante da ausência de protocolo da ocorrência das atividades, demandas técnicas específicas dos cursos, e da necessidade de orientar a comunidade acadêmica do referido centro, foi instalado o Grupo de Trabalho do Centro de Tecnologia composto por representantes docentes, discentes e técnico-administrativos. Destarte, a partir da análise situacional foi possível levantar as percepções dos entes universitários e propor medidas que relacionam uma retomada acadêmica segura, inclusiva e com mínimos prejuízos à qualidade do ensino ofertado.

Palavras-chave: Pandemia. Retomada. Tecnologia. Gestão.

\section{INTRODUÇÃO}

De acordo com os provimentos do Conselho Universitário (CONSUNI), as atividades acadêmicas presenciais foram suspensas, em consonância com os decretos de isolamento social. Além disso, houve a recomendação de prosseguimento por meio de atividades remotas. Nesse contexto, a Pró-Reitoria de Graduação (PROGRAD) realizou estudos das normativas e acompanhamento das atividades junto às unidades acadêmicas constituintes da UFC. Em maio de 2020, foi instalado o Grupo de Trabalho (GT) da PROGRAD para a elaboração de um Plano Pedagógico de Emergência (PPE) em que se partiu da situação em que ocorria os cenários de continuidade e desdobramentos mostrados na Tabela 1.

Tabela 1: Cenários de continuidade acadêmica e possíveis desdobramentos.

\begin{tabular}{|c|c|}
\hline Situação & Desdobramentos \\
\hline Turmas com ocorrência de & Alunos acompanhando \\
\cline { 2 - 2 } atividades remotas & Alunos não acompanhando \\
\hline Turmas que interromperam as & Por serem teórico-práticas \\
\cline { 2 - 2 } atividades remotas & Por baixa adesão dos estudantes \\
\hline Turmas que não iniciaram as & Por decisão dos conselhos \\
\hline
\end{tabular}


"Os desafios para formar hoje o engenheiro do amanhã"

atividades remotas

Não adesão dos professores

Por serem totalmente práticas ou de difícil adaptação digital

Fonte: Pró-Reitoria de Graduação UFC (2020).

Desse modo, é necessário destacar as contingências dos cursos do CT, os quais possuem significativa carga horária prática. Esta distribuição atividades de laboratório e campo está descrita na Tabela 2. A Portaria 343/2020 do Ministério da Educação, restringiu a aplicação de substituição de atividades para as práticas profissionais e de laboratório para estes cursos. Além disso, nos Planos Pedagógicos de Cursos não estão previstas atividades na modalidade de ensino à distância. Destarte, percebeu-se a necessidade de adaptar as percepções, discussões e propostas da Administração Superior às demandas dos cursos do Centro de Tecnologia.

Tabela 2: Participação de carga horária prática nos cursos do Centro de Tecnologia.

\begin{tabular}{|c|c|c|c|}
\hline Curso & C.H. Prática & C.H. Total & $\%$ Prática \\
\hline Arquitetura e Urbanismo & 1088 & 4032 & $27 \%$ \\
\hline Design & 1328 & 3200 & $42 \%$ \\
\hline Engenharia Ambiental & 512 & 3664 & $14 \%$ \\
\hline Engenharia Civil & 368 & 3600 & $10 \%$ \\
\hline Engenharia de Computação & 580 & 3600 & $16 \%$ \\
\hline Engenharia de Energias Renováveis & 592 & 3504 & $17 \%$ \\
\hline Engenharia de Petróleo & 368 & 3792 & $10 \%$ \\
\hline Engenharia de Produção Mecânica & 176 & 3600 & $5 \%$ \\
\hline Engenharia de Telecomunicações & 608 & 3600 & $17 \%$ \\
\hline Engenharia de Teleinformática & 384 & 3600 & $11 \%$ \\
\hline Engenharia Elétrica & 544 & 3600 & $15 \%$ \\
\hline Engenharia Mecânica & 504 & 3600 & $14 \%$ \\
\hline Engenharia Metalúrgica & 416 & 3600 & $12 \%$ \\
\hline Engenharia Química & 842 & 3768 & $22 \%$ \\
\hline
\end{tabular}

Fonte: Sistema Integrado de Gestão de Atividades Acadêmicas.

Portanto, a Portaria 31/2020 da Diretoria do Centro de Tecnologia foi instalado o Grupo de Trabalho para a elaboração um Protocolo de Retorno Pós-Pandemia voltado aos cursos do referido centro. A equipe composta por doze membros, os quais incluem professores, alunos e representantes técnico-administrativos.

Os objetivos principais são: compreender os problemas decorrentes da situação provocada pela pandemia, na percepção da comunidade acadêmica do CT, bem como os desdobramentos sobre as atividades desenvolvidas. Além de apresentar cenários com proposição de ações. O objetivo específico é a elaboração de um protocolo de continuidade acadêmica remota e retorno às atividades presenciais contemplando cinco eixos: pessoal, biossegurança, currículo, capacitação e infraestrutura.

Por conseguinte, o conjunto pessoal contempla a situação social, sanitária e psicológica dos entes universitários. A categoria de biossegurança está relacionada ao contato com especialistas no assunto e revisão bibliográfica para a indicação de diretrizes que sustentem um retorno presencial seguro. Os componentes currículo e capacitação orientam a busca pela transição na oferta de ensino que visa reduzir os impactos negativos na aprendizagem, além de oferecer experiências de formação para elaboração e acompanhamento das atividades remotas. Por fim, o levantamento da infraestrutura busca verificar quais espaços podem ser 
adaptados para a utilização da comunidade acadêmica visando ao acesso aos recursos digitais e posterior retomada presencial.

\section{METODOLOGIA}

Foi estabelecido o fluxo de trabalho apresentado na Figura 1, inicia-se com o diagnóstico de problemática, aliado aos planos de formação e capacitação para as atividades remotas. Posteriormente, de acordo com as condições de biossegurança e infraestrutura foram propostas diretrizes para a reposição presencial das atividades laboratoriais. Em paralelo a essas atividades, foram abertos canais de comunicação oficiais junto à comunidade acadêmica. Após isso, o produto obtido é o plano de orientação da retomada remota e a mediação de casos especiais para a oferta de uma continuidade segura, viável e inclusiva.

Figura 1: Fluxo de trabalho simplificado

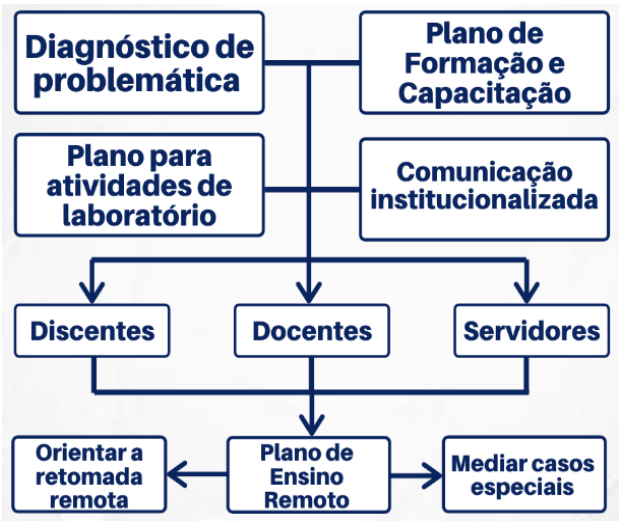

Fonte: GT Centro de Tecnologia (2020)

\subsection{Diagnóstico Discente}

Esta etapa foi realizada entre os dias 01/06/2020 e 18/06/2020 a partir de um plano amostral que contempla todos os cursos do Centro de Tecnologia que visa à margem de erro de 4\%. Também disponibilizado para os alunos responderem de forma anônima. $\mathrm{O}$ formato do questionário foi inspirado no Questionário de Vivências Acadêmicas - versão reduzida (QVA-r) (ALMEIDA; FERREIRA; SOARES, 2003) e nos estudos de adaptação e permanência no ensino superior em tempos de pandemia (AMBIEL et al., 2020).

Desse modo, o instrumento é dividido em duas partes, a primeira contempla dados gerais para a caracterização da amostra, tendo perguntas comuns a todos os participantes. A segunda parte, é definida a partir da resposta acerca da realização de atividades remotas, são consideradas as dimensões pessoal, social, carreira, estudo, avaliações docente e institucional. Os elementos relacionados às categorias estão descritos na Tabela 3.

Tabela 3: Dimensões do QVA-R em tempos de pandemia.

\begin{tabular}{|c|c|}
\hline Dimensão & Elementos relacionados e avaliados \\
\hline Pessoal & Bem estar físico e psicológico, equilíbrio emocional, otimismo, autoconfiança. \\
\hline Social & Relações com os amigos, colegas e família e aspectos financeiros. \\
\hline Docente & $\begin{array}{c}\text { Comunicação e relação com os professores, avaliação de metodologias de } \\
\text { ensino e das tecnologias utilizadas }\end{array}$ \\
\hline Carreira & $\begin{array}{c}\text { Impactos da pandemia na percepção sobre o curso, perspectivas de carreiras e } \\
\text { projetos vocacionais. }\end{array}$ \\
\hline Estudo & $\begin{array}{c}\text { Hábitos de estudo, gestão de tempo, utilização dos recursos de aprendizagem } \\
\text { no contexto de atividades remotas. }\end{array}$ \\
\hline Institucional & Modo como a instituição de ensino tem respondido ao atual contexto de \\
\hline
\end{tabular}




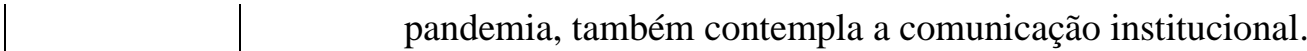

Fonte: GT Centro de Tecnologia (2020)

Foi adotado o formato Likert para as respostas, o que apresenta cinco níveis de resposta consoante o grau de acordo com os estudantes. Posteriormente, foi realizado o cálculo da média das dimensões tratadas, assim as perguntas com sentido negativo têm a pontuação de escala invertida. Desse modo, quanto mais próximo de 5, mais pertinente é a relação entre o aluno e a assertiva proposta. Além das médias por dimensão, também foi obtida a média geral que serve como indicador de adaptação à situação de transição entre o modelo presencial e o remoto.

\subsection{Diagnóstico Docente}

A pesquisa realizada em simultâneo com o levantamento com os alunos. O instrumento é dividido em três partes. Inicialmente, foi perguntado acerca de questões de ordem pessoal cujo objetivo principal é obter informações acerca do bem estar físico e psicológico dos professores, considerando a ocorrência de comorbidades, por exemplo. Posteriormente, investigou-se as condições de acesso às tecnologias de informação e condições de execução de atividades de forma remota. Em seguida, foi identificado quantos professores já estavam utilizando o ensino híbrido e quais ferramentas, plataformas e ambientes virtuais. Nesse contexto, é possível identificar as demandas por capacitação e aparatos técnicos.

Dessa forma, foi realizado o levantamento da situação das turmas, o qual contempla a quantidade de alunos, turmas e disciplinas ministradas. $\mathrm{O}$ que permite conhecer um macro perfil de ensino e aprendizagem para os componentes curriculares. O questionário com perguntas objetivas e discursivas foi enviado por $e$-mail e respondido de forma anônima.

\subsection{Plano de Retomada dos Laboratórios}

Verificou-se que $41 \%$ dos componentes curriculares são teórico-práticos ou práticos, os quais estão impedidos de promoverem reposição integral das atividades pelo modelo remoto. Entretanto, é possível propor continuidades de transmissão de conteúdos relacionados às práticas, o que evita a interrupção completa da turma e promove o combate ao abandono ou trancamento de disciplina. Desse modo, as atividades foram categorizadas em três grupos: Turmas com conteúdo expositivo, práticas realizadas pelo docente, técnico laboratorial ou monitor; turmas com participação parcial dos alunos na realização da prática e turmas com práticas realizadas integralmente pelo estudante, a qual inclui os trabalhos de campo.

A divisão das atividades foi realizada junto ao questionário de diagnóstico docente, em que foi verificada também a possibilidade de realização individual ou em grupo, e qual o menor grupo possível. Destarte, foram avaliadas as questões relacionadas à infraestrutura do espaço físico, utilização de equipamentos, demanda por insumos para a realização das práticas e de equipamentos de proteção individuais e/ou coletivos.

\subsection{Elaboração de Diretrizes}

A partir dos dados levantados na fase de diagnóstico e percepções enviadas por contribuintes da comunidade acadêmica, o Grupo de Trabalho do Centro de Tecnologia realizou reuniões semanais para a deliberação de propostas de diretrizes para submeter ao Conselho de Centro. O documento elaborado está em consonância com os decretos governamentais e a Proposta Pedagógica de Emergência emitida pela PROGRAD. Nesse contexto, foram elaboradas premissas próprias e diretrizes as quais visam evitar a supressão em massa de matrículas, orientar e ordenar as atividades remotas respeitando a liberdade de 
(C) COBENCE 2020

"Os desafios para formar hoje o engenheiro do amanhã"
O1 a $\mathrm{O3}$ de dezembro

Evento On-line

cátedra docente e possibilitar o acesso dos alunos, nivelando por aqueles que possuem menos recursos.

\section{RESULTADOS}

\subsection{Diagnóstico Discente}

A participação do plano amostral foi atingida em todos os cursos. Em suma, foram registradas 1.291 respostas (31,34\% do corpo discente do CT). A Figura 2 apresenta as estatísticas relacionadas aos dados gerais, em que a maioria respondente é do sexo masculino (64\%), aproximadamente $80 \%$ estão na faixa etária de 18 a 23 anos. Quanto à localização, os resultados apontam 68\% para Fortaleza, 16\% para municípios da Região Metropolitana de Fortaleza, 14\% estão em outros municípios do Ceará, 2\% estão em outros estados do Brasil e $0,15 \%$ reportaram localização internacional. Na imagem a seguir, também estão registradas estatísticas relacionadas ao acesso à Internet e disponibilidade dos equipamentos, em que a maioria aponta acesso à banda larga e equipamento próprio e de uso exclusivo.

Figura 2: Infográfico com dados gerais discentes.

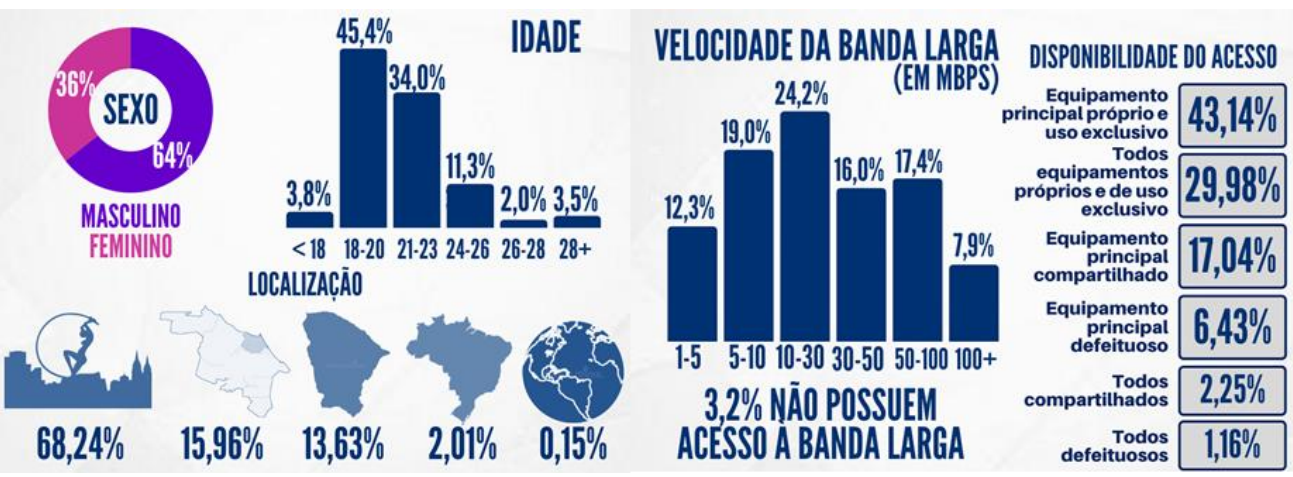

Fonte: GT Centro de Tecnologia (2020)

Foi observada a participação de $48 \%$ dos alunos nas atividades remotas e preferência pela interação assíncrona, quando os conteúdos são disponibilizados para que o aluno construa seu próprio fluxo de aprendizagem. Essas estatísticas estão apresentadas na Figura 3.

Figura 3: Infográfico com dados acerca da participação em atividades remotas.
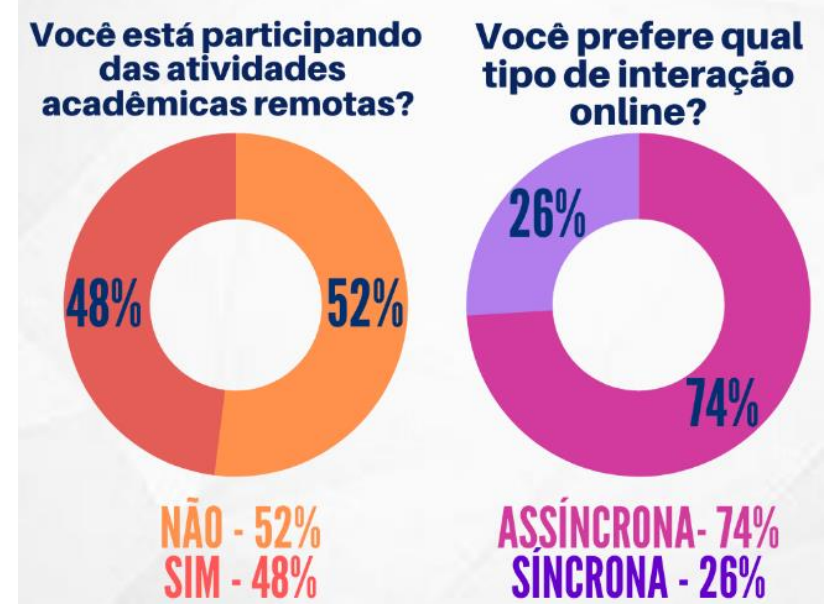

Fonte: GT Centro de Tecnologia (2020) 
(C) COBENGE

"Os desafios para formar hoje o engenheiro do amanhã"

As três assertivas mais pertinentes relacionadas às dimensões do Questionário de Vivências Acadêmicas em tempos de pandemia estão na Tabela 4, além da média da dimensão considerando todas as respostas. A média geral do QVA-R apontada foi de 3,95.

Tabela 4: Principais tendências discentes para as dimensões do QVA-R.

\begin{tabular}{|c|c|c|}
\hline Dimensão & Assertiva & Média \\
\hline \multirow{3}{*}{$\begin{array}{c}\text { Pessoal } \\
(2,78)\end{array}$} & Faço atividades de lazer e entretenimento & 3,63 \\
\hline & Procuro manter limites na busca de informação sobre a pandemia & 3,46 \\
\hline & Sinto necessidade de acompanhamento psicológico & 3,08 \\
\hline \multirow{3}{*}{$\begin{array}{l}\text { Social } \\
(3,25)\end{array}$} & Cuido para me manter conectado às pessoas que amo & 3,85 \\
\hline & Tenho amigo (s) com quem posso desabafar & 3,72 \\
\hline & Estou preocupado em perder a bolsa/auxílio da UFC & 3,69 \\
\hline \multirow{3}{*}{$\begin{array}{c}\text { Docentes } \\
(2,91)\end{array}$} & Sinto-me feliz com a forma como meus professores me tratam & 3,42 \\
\hline & Gosto das plataformas digitais e aplicativos utilizados & 3,15 \\
\hline & Considero adequada a avaliação feita nas disciplinas remotas & 2,83 \\
\hline \multirow{3}{*}{$\begin{array}{c}\text { Estudo } \\
(2,99)\end{array}$} & Consigo utilizar com facilidade as plataformas digitais para atividades & 4,01 \\
\hline & As tarefas domésticas têm atrapalhado meus estudos & 3,53 \\
\hline & Faço pausas/intervalos entre os estudos & 3,53 \\
\hline \multirow{3}{*}{$\begin{array}{c}\text { Institucional } \\
(3,23)\end{array}$} & Gostaria de concluir o meu curso na instituição atual & 4,54 \\
\hline & A Coordenação de Curso tem respondido ágil e atenciosamente online & 3,21 \\
\hline & Costumo acessar os perfis da UFC nas redes sociais & 3,12 \\
\hline
\end{tabular}

\subsection{Diagnóstico Docente}

Foram registradas 179 respostas, o que representa 75,21\% do corpo docente. Nos onze departamentos constituintes do CT, a participação esteve entre 64\% e 100\%. Na categoria saúde, 9 docentes testaram positivo para o Covid-19 e 55\% encontram-se em algum grupo de risco. A Figura 4 traz o detalhamento das ocorrências apontadas pelos docentes.

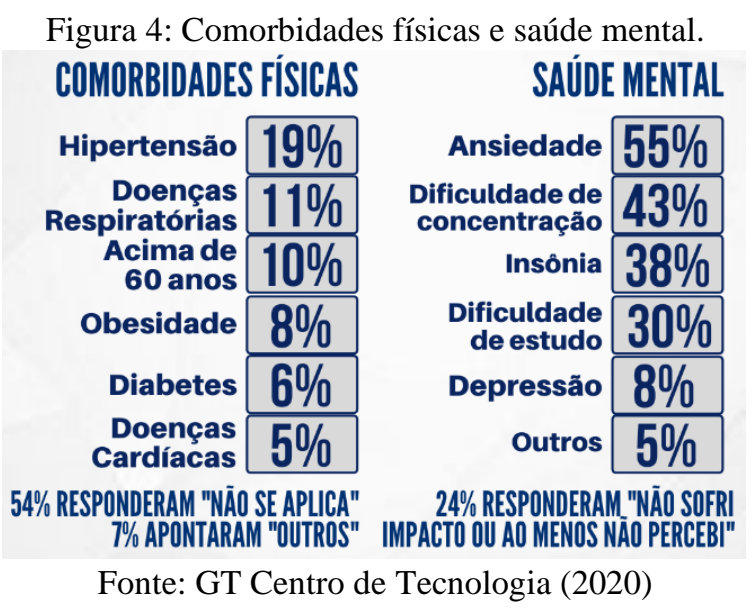

Acerca da infraestrutura, 33\% apontaram não dispor de ambiente adequado para rotinas de trabalho acadêmico. Quanto aos equipamentos de áudio e vídeo, $46 \%$ apontam possuir equipamentos adequados para a geração de conteúdo, enquanto $39 \%$ não dispõem de nenhum equipamento. $11 \%$ apontam apenas instrumentos para gravação de áudio e $4 \%$ apenas aparato para geração de vídeo.

As experiências remotas apontadas constituem as tendências apontadas pela Tabela 5, no qual a maioria não informou experiência com ensino à distância. Há frequência majoritária positiva para o conhecimento de algum ambiente virtual de aprendizagem, interesse em 


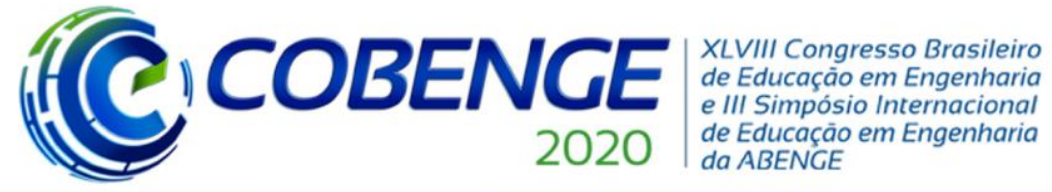

"Os desafios para formar hoje o engenheiro do amanhã"

participação de capacitações ofertadas pelo CT e esperança pela retomada do semestre 2020.1 em modo remoto. Quanto às potenciais dificuldades, foi apontado por $27 \%$ dos docentes, a falta de equipamento adequado, seguido por formação nas metodologias (26\%) e ambiente adequado (25\%). 20\% dos docentes não apontaram problemas.

Tabela 5: Experiências remotas docentes.

\begin{tabular}{|c|c|c|}
\hline Pergunta & Sim & Não \\
\hline Já trabalhou com ensino à distância? & $26,52 \%$ & $73,48 \%$ \\
\hline Conhece algum ambiente virtual de aprendizagem? & $61,33 \%$ & $38,67 \%$ \\
\hline $\begin{array}{c}\text { Caso o CT ofereça treinamentos para ferramentas. } \\
\text { Você tem interesse de participar? }\end{array}$ & $88,95 \%$ & $11,05 \%$ \\
\hline $\begin{array}{c}\text { Você espera que a retomada do semestre 2020.1 } \\
\text { ocorra de forma remota? }\end{array}$ & $85,08 \%$ & $14,92 \%$ \\
\hline
\end{tabular}

Fonte: GT Centro de Tecnologia (2020)

\subsection{Ciclo de Formação Docente}

Devido aos apontamentos do diagnóstico docente, o Grupo de Trabalho convidou os professores a acompanhar uma série de lives sobre a transição entre método presencial e remoto e utilização de equipamentos e ferramentas. As atividades do Ciclo de Formação Docente ocorreram entre os dias 02/07/2020 e 05/08/2020, os conteúdos foram gravados e disponibilizados aos docentes que não puderam acompanhar a transmissão ao vivo. As atividades propostas também foram abertas aos docentes fora da UFC. A Tabela 6 apresenta os eventos e as datas de transmissão.

Tabela 6: Ciclo de formação docente.

\begin{tabular}{|c|c|c|}
\hline Data & Assunto & Docentes inscritos \\
\hline $02 / 07 / 2020$ & Ensino remoto, EAD e ensino híbrido: Qual a diferença? & 103 \\
\hline $06 / 07 / 2020$ & Planejamento e construção do plano de ensino & 35 \\
\hline $10 / 07 / 2020$ & Capacitação sobre vídeo-aula & 38 \\
\hline $14 / 07 / 2020$ & Experiências no ensino remoto da disciplina de Sistemas Distribuídos & 20 \\
\hline $15 / 07 / 2020$ & Avaliação da aprendizagem em contexto de pandemia & 34 \\
\hline $22 / 07 / 2020$ & Aprendizagem cooperativa & 19 \\
\hline $29 / 07 / 2020$ & Podcast (teoria) & 25 \\
\hline $05 / 08 / 2020$ & Podcast (tira-dúvidas) & 25 \\
\hline
\end{tabular}

Fonte: GT Centro de Tecnologia (2020)

\subsection{Plano de Retomada dos Laboratórios}

A partir dos dados oriundos do diagnóstico docente, foi possível perceber que $46 \%$ dos professores ministram disciplinas com prática. Foi observado que para $48 \%$ dos docentes, o aluno é responsável direto total pelo experimento e $27 \%$ apontam que o aluno é responsável direto parcial. Nesse ínterim, para 59\%, as atividades podem ser realizadas de forma individual, também foi perguntado qual a seria a menor configuração de grupo possível com respostas absolutas dos docentes. A Figura 5 aponta esses resultados. 


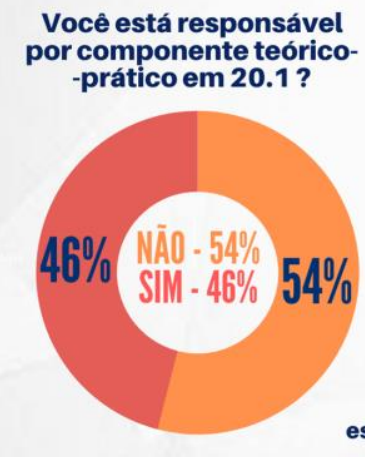

Você está responsável - componente teorico-$$
\text { estu }
$$$$
\begin{gathered}
\text { Apenas alguns } \\
\text { estudantes participam }
\end{gathered}
$$
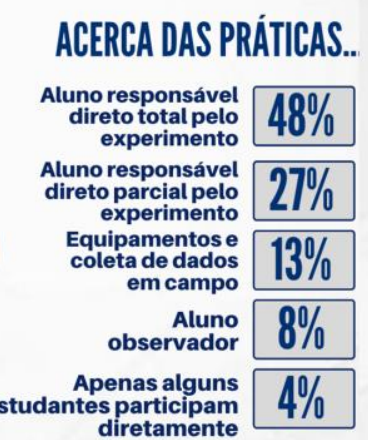

Figura 5: Disciplinas teórico-práticas

Fonte: GT Centro de Tecnologia (2020)
As atividades teórico-
práticas só podem ser realizadas em grupos?

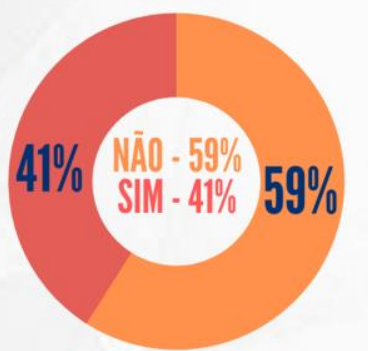

Qual o menor grupo possível?

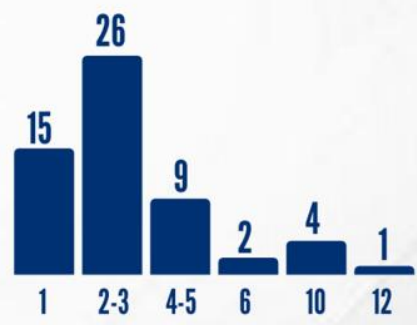

A partir das informações captadas, o Departamento de Engenharia Elétrica preparou um modelo relatório de viabilidade da adaptação dos Laboratórios de Eletrotécnica. Inicialmente, foi realizado o levantamento de demanda das disciplinas, o que resultou em 395 alunos em 3 componentes curriculares. Foram contemplados o distanciamento mínimo, sinalização de locais de circulação, ventilação dos espaços e áreas de convivência e livres. A Figura 6 informa a configuração de espaço para as bancadas do laboratório do Bloco 705 do Campus do Pici. A orientação repassada foi que o núcleo teórico seja estudado remotamente antes da prática para que o tempo em laboratório seja plenamente utilizado para as montagens.

Figura 6: Configuração das bancadas do Laboratório de Eletrotécnica do Bloco 705.
Bancada 4

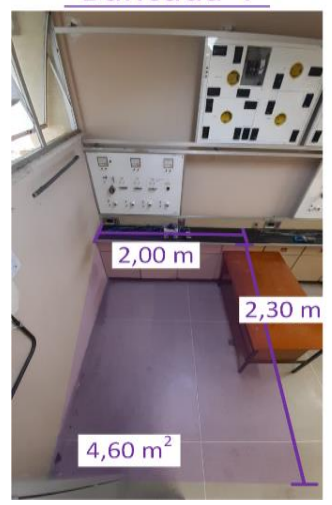

Fonte: Departamento de Engenharia Elétrica UFC (2020)
Bancada 2

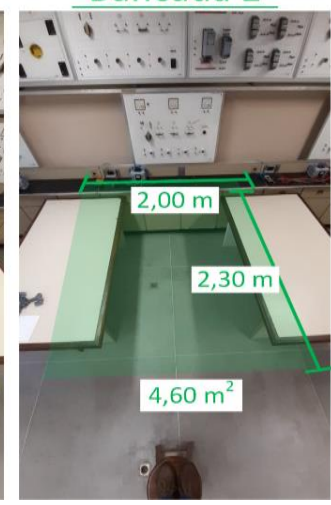

Bancada 3

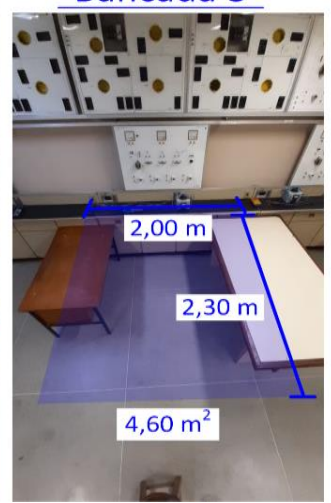

Bancada 1

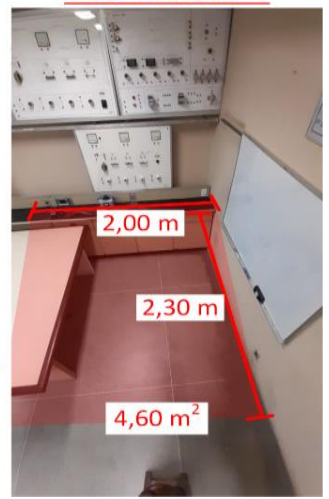

\subsection{Elaboração de Diretrizes}

As atividades administrativas no modo remoto foram regulamentadas, de forma a manter a prestação dos serviços essenciais ao Centro de Tecnologia, com a promoção de fluxos de atendimento organizado e a partir de orientações da Diretoria Adjunta de Ensino (DAE). Para as atividades administrativas e teóricas presenciais, além de laboratoriais foram atribuídas a implantação de procedimentos relativos à segurança sanitária e interações com reduções de turmas originalmente constituídas e os tempos de interação também serão controlados, respeitando o máximo de 50 minutos consecutivos. Por fim, também foi proposto o questionário de estado de saúde de estudantes e professores para avaliar o retorno presencial.

\section{CONCLUSÕES}

Destarte, foi possível considerar que a partir das percepções apontadas, que a carga horária teórica-prática é um elemento significativo para a continuidade acadêmica e que seu 
protocolo específico é uma demanda que pode ser adaptada às contingências de cada laboratório, mantendo elementos comuns referentes às orientações apresentadas no documento de diretrizes para retomada de atividades administrativas e acadêmicas. Este documento foi apresentado e aprovado em sessão do Conselho de Centro do CT no dia 13 de julho de 2020.

A ampla participação da comunidade acadêmica foi observada, visto que foi mantido o diálogo com as coordenações de curso, representações estudantis e técnico-administrativos. Além disso, disponibilizou-se um endereço de e-mail para a comunicação. Quanto aos resultados de diagnósticos, muitos foram convertidos em diretrizes para o ensino, como a promoção das atividades assíncronas, garantia de suporte pedagógico e tecnológico, flexibilização do controle de frequência, possibilidades de avaliação alternativas, elaboração do plano de aula remoto para cada turma em conjunto com os alunos. As ações propostas visaram que não ocorresse a supressão em massa de matrículas, fornecendo a alternativa da migração de turma em mediação com o docente e a coordenação de curso.

Em uma perspectiva de qualificação, o Ciclo de Formação Docente foi bem recebido pelos professores do centro, com participação relevante destes nas atividades, sobretudo para a orientação das diferentes modalidades de ensino e capacitação em ferramentas digitais. Os planos laboratoriais seguem as orientações propostas pelo Grupo de Trabalho e sua implantação está sob critério dos responsáveis competentes diretos.

Pode-se afirmar que o método proposto consegue contemplar a compreensão de situação microscópica, no âmbito do modo como os docentes estão tratando a continuidade do ensino em seus componentes curriculares. Mas também, em situação macroscópica, fornecendo um painel situacional e de tendências, utilizado para direcionar ações de órgãos gestores. A sugestão de continuidade para este estudo é a avaliação de seus resultados.

\section{Agradecimentos}

Aos colegas membros do GT Centro de Tecnologia pela diligência na condução dos trabalhos e autorização de publicação: Alice Oliveira Gurgel, André Bezerra de Holanda, André Lima Férrer de Almeida, Antônio Macário Cartaxo de Melo, Ariane Cavalcante Nogueira Lima, Bruno Vieira Bertoncini, Ivanildo José da Silva Júnior, Marcelo Ferreira Motta, Raphael Amaral da Câmara, Renan Cid Varela Leite e Yangla Kelly Oliveira Rodrigues. Aos professores Carlos Almir Monteiro de Holanda e Diana Cristina Silva de Azevedo, diretor e vice-diretora, respectivamente do Centro de Tecnologia da UFC, pelo apoio e diligência dispensados ao Grupo de Trabalho.

\section{REFERÊNCIAS}

ALMEIDA, L. S.; SOARES, A. P. C.; FERREIRA, J. A. Questionário de Vivências Acadêmicas (QVA-r): avaliação do ajustamento dos estudantes universitários. Avaliação Psicológica, Porto Alegre, v.1, n.2, 2002.

AMBIEL, R. A. M. et al. Adaptação e permanência no Ensino Superior em tempos de pandemia. Universidade de São Francisco, 2020.

Diretrizes para Retomada as Atividades Administrativas e Acadêmicas no Centro de Tecnologia da Universidade Federal do Ceará. Grupo de Trabalho do CT UFC, 2020. 
HONÓRIO, Dalton de Araújo; BRANDÃO, Eliezer Ribeiro da Silva. Relatório de viabilidade da adaptação dos Laboratórios de Eletrotécnica do DEE UFC (Campus do Pici) às diretrizes do PPE da PROGRAD. Depto. de Engenharia Elétrica UFC, 2020.

MAGALHÃES, M. O. Sucesso e fracasso na integração do estudante à universidade: um estudo comparativo. Revista Brasileira de Orientação Profissional, Salvador, v.14, n.2, p. 215-226, 2013.

Ministério da Educação. Protocolo de biossegurança para retorno das atividades nas Instituições Federais de Ensino. Disponível em: https://www.gov.br/mec/pt-br/centrais-deconteudo/campanha/coronavirus/CARTILHAPROTOCOLODEBIOSSEGURANAR101.pdf/ Acesso em: 04 jul. 2020.

Nota à comunidade acadêmica do CT. Grupo de Trabalho do CT UFC, 2020.

Universidade Federal do Ceará. Provimentos do Conselho Universitário (CONSUNI) 2020. Disponível em: http://www.ufc.br/a-universidade/documentos-oficiais/14316provimentos-do-conselho-universitario-consuni-2020. Acesso em: 09 ago. 2020.

Universidade Federal do Ceará. Pró-Reitoria de Graduação. Plano Pedagógico de Emergência. Disponível em: https://prograd.ufc.br/wp-content/uploads/2020/08/planopedagogico-de-emergencia-ppe.pdf. Acesso em: 09 ago. 2020.

\title{
PROPOSAL FOR THE ACADEMIC RETURN PLAN OF THE FEDERAL UNIVERSITY OF CEARÁ TECHNOLOGY CENTER
}

\begin{abstract}
:
The occurrence of the COVID-19 pandemic forced the interruption of numerous face-to-face activities. In this context, university education was directly affected, since many teaching methods are still supported in classroom, expository and oral classes. Ceará reached high levels of coronavirus infection in March 2020, which supported the provision of the UFC Rectory for the interruption of face-to-face functions and their remote exercise. In this way, the UFC Technology Center (CT) comprises courses in Architecture, Design and Engineering; which are in the reform phase of the Curricular Pedagogical Proposals and therefore are discussing new and active teaching and learning methodologies. In view of the absence of a protocol for the occurrence of activities, specific technical demands of the courses, and the need to guide the academic community of the referred center, the Working Group of the Technology Center was installed, composed of teaching, student and technicaladministrative representatives. Thus, from the situational analysis it was possible to raise the perceptions of university entities and propose measures that relate to a safe, inclusive academic resumption and with minimal damage to the quality of the education offered.
\end{abstract}

Keywords: Pandemy. Return. Technology. Management. 